\title{
Fixation of Winged Scapula in Facioscapulohumeral Muscular Dystrophy
}

\author{
Sandro Giannini, MD; Cesare Faldini, MD; Stavroula Pagkrati, MD; Gianluca Grandi, MD; \\ Vitantonio Digennaro, MD; Deianira Luciani, MD; and Luciano Merlini, MD
}

\begin{abstract}
Objective: To verify if stabilizing the scapulothoracic joint without arthrodesis could lead to functional improvement of shoulder range of motion and clinical improvement of winged scapula, we incorporated four additional patients into our previous analysis to determine if the results obtained were long lasting, and to compare this fixation with the other techniques described in the literature, balancing the benefits with the complications.
\end{abstract}

Design: A retrospective study.

Participants: Thirteen patients with bilateral winged scapula affected by facioscapulohumeral muscular dystrophy. Nine of these patients had been analyzed in our previous study.

Methods: Patients were operated on by bilateral fixing of the scapula to the rib cage using metal wires without arthrodesis (scapulopexy).

Results: All patients experienced improvement in active range of motion of the shoulder and all of them had clinical improvement with complete resolution of the winged scapula. In all twenty-six surgical interventions of scapulopexy, a stable and long-lasting fixation of the scapula to the rib cage was achieved. The complications strictly associated to the surgical technique encountered were one pneumothorax, which was resolved spontaneously, and one wire breakage without trauma. Average follow-up was 10 years (range, 3 to 18 years).

Conclusion: The scapulopexy used in this extended series of patients consisted of repositioning the scapula and fixing it to four ribs by using metal wires without performing arthrodesis. This technique has a low rate of complications, is reproducible, safe and effective, resulting in clinical and functional improvement.

\section{Keywords: Muscular dystrophy; Scapulopexy; Winged scapula}

$\mathrm{F}$ acioscapulohumeral (FSH) muscular dystrophy, initially described by Landouzy and Dejerine, represents one of the most frequent congenital myopathies. ${ }^{1-7}$ It is an autosomal dominant myopathy, although $10 \%$ to $30 \%$ of the cases arise from de novo mutation. The onset can be at any age, but symptoms commonly begin in the second decade of life. FSH muscular dystrophy has a complete penetrance but variable expressivity, so the spectrum of clinical presentation can vary from mild to severe cases. ${ }^{1,6,8}$ FSH muscular dystrophy is characterized by prevalent weakness of facial and proximal upper limb muscles that progresses very slowly. Facial weakness causes an amimic, smooth face with inability to purse the lips and incomplete eye closure. Shoulder girdle weakness is the most constant feature of this disease and leads to scapular winging. Other muscles can also be involved by the myopathy, such as neck muscles, hip muscles with a compensatory lumbar lordosis, and muscles of the anterior portion of the leg leading to foot drop. ${ }^{1,4,6,8}$ 

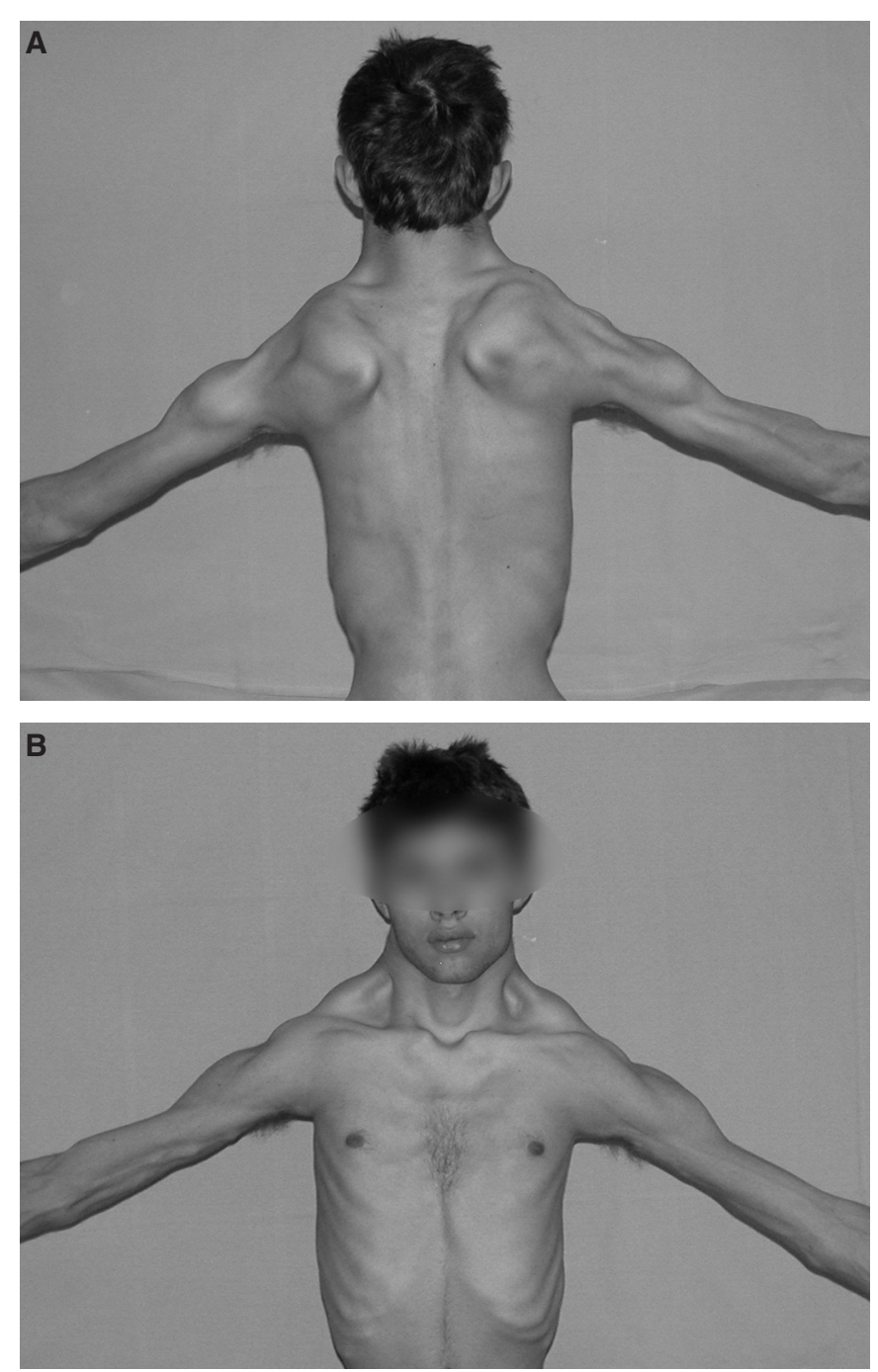

Figure 1. An 18-year-old patient affected by facioscapulohumeral muscular dystrophy. (A) During active arm abduction, the scapula abnormally internally rotates, becoming winging, and the range of motion is limited. $(B)$ The upper border of the scapula produces an abnormal profile of the neck. Note the characteristic aspect of the mouth caused by weakness of the face muscles and the excessive contraction of the auxiliary muscles, such as the sternocleidomastoid.

During the physiological movements of the shoulder, the scapulothoracic joint muscles stabilize the scapula to the rib cage. While the contraction of the glenohumeral joint muscles is mainly responsible for the first $90^{\circ}$ of abduction, the remaining $90^{\circ}$ of shoulder abduction is produced by a synergic movement of the muscles of both joints. Shoulder girdle instability in FSH muscular dystrophy is caused by weakness of the muscles, which normally stabilize the scapula to the rib cage. When a patient affected by FSH muscular dystrophy tends to abduct or forward flex the shoulder, the scapula cannot be held to the rib cage because of weakness of the scapulothoracic joint muscles. Consequently, the contraction of the spared glenohumeral joint muscles produces an initial abduction of the shoulder and at the same time an abnormal scapular internal rotation. ${ }^{9-11}$
The clinical and functional consequences of these biomechanical changes of the shoulder motion are scapular winging, and limitation of shoulder flexion and abduction (figure 1). At rest position, scapular asymmetry is noted, while scapular winging is a dynamic deformity with cosmetic dissatisfaction of the patients. Patients get easily tired and are unable to hold heavy objects or perform overhead activities, such as combing hair or shaving, but they do not complain of pain. ${ }^{12-14}$

Patients affected by FSH muscular dystrophy who present with scapular winging can be treated by scapular stabilization. The stabilization can be carried out by nonoperative or surgical techniques. Conservative treatment consists of application of an orthotic device, which presses the scapula to the rib cage, stabilizing it temporally. ${ }^{15}$ These orthoses can be cumbersome, difficult for patients to accept, and improvement in shoulder movement is present only during their use. For these reasons, conservative treatment is not suggested. Surgical correction of winged scapula is the treatment of choice because it fixes the scapula permanently to the rib cage. ${ }^{16}$ This fixation can be obtained by different techniques, which are grouped into scapulothoracic fusion or arthrodesis (scapulodesis) 12,13,17-27 and scapulothoracic fixation without arthrodesis (scapulopexy). ${ }^{14,28-31}$

An alternative surgical technique of scapulopexy was described by Giannini et al in $1992 .{ }^{29}$ In the present paper, this technique was used in a series of thirteen patients with bilateral winged scapula affected by FSH muscular dystrophy. Nine of these patients had been analyzed previously. ${ }^{14}$ The aim of the study was to verify if fixing the scapula to the rib cage using metal wires without arthrodesis could lead to functional and clinical improvement, if the results obtained were long-lasting, and to compare this fixation with the other techniques described in the literature, balancing the benefits with the complications.

\section{Methods}

Between 1983 and 2003, 26 shoulders in thirteen patients with winged scapula, secondary to FSH muscular dystrophy, had fixation of the scapula by scapulopexy. Nine of these patients had been analyzed previously. ${ }^{14}$

The diagnosis of FSH muscular dystrophy was based on family history, age of first symptoms onset, estimation of creatine kinase activity and muscular biopsy. In ten patients, genetic analysis was performed in order to confirm the diagnosis of FSH muscular dystrophy. Clinically, all patients presented bilateral shoulder anteposition and scapular winging, and they were all ambulatory.

As the severity and presentation of FSH muscular dystrophy can vary from patient to patient, surgical selection was performed regardless of the patient's age, and the correct timing for surgery was considered when a patient had developed a severe scapulothoracic joint weakness associated 

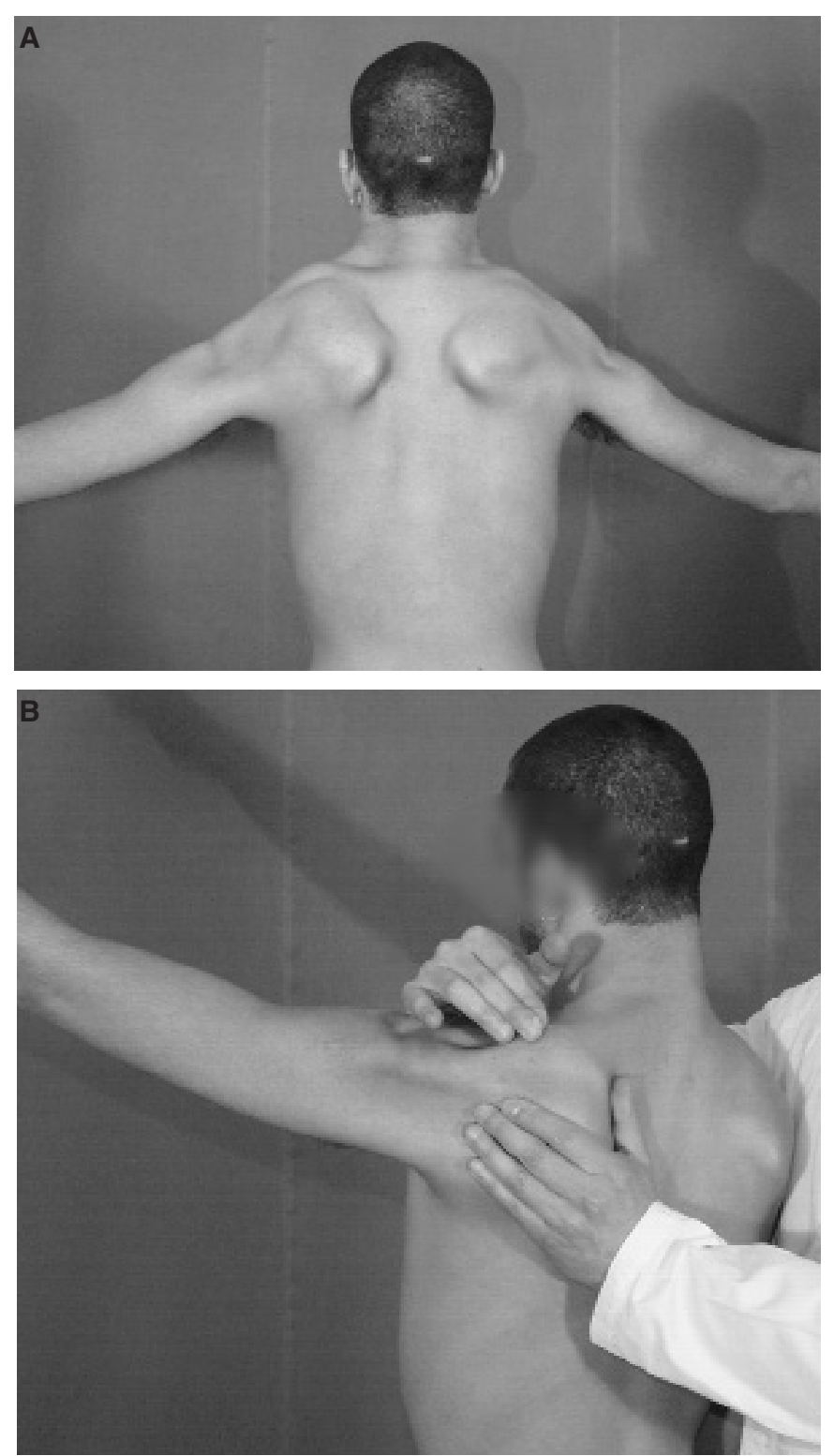

Figure 2. An 18-year-old patient affected by facioscapulohumeral dystrophy. (A) The active shoulder abduction is limited. (B) Positive Horwitz maneuver: if the glenohumeral joint muscles are preserved, active shoulder range of motion improves when the scapula is held manually against the rib cage.

with good function of the glenohumeral joint. To decide if a patient would be a candidate for intervention, the Horwitz maneuver was performed preoperatively. ${ }^{32}$ The physician holds the patient's scapula against the rib cage, while the patient tries to raise the arm. If the arm is actively flexed or abducted (positive Horwitz maneuver), then intervention is indicated (figure 2). If the patient is unable to improve the shoulder range of motion, then surgery is unlikely to improve the patient's function because of the weakness of the glenohumeral joint muscles, thus physiotherapy is usually indicated. Three patients were excluded from the study because they had a negative Horwitz maneuver; they received physiotherapy but no surgery.
This series included seven women and six men. Diagnosis of FSH muscular dystrophy was made at a mean age of 24 years (range, 13 to 36 years). All patients complained of limitation in activities of daily life and easy fatigue, but none had pain. Radiographs of both scapula were performed in two views, at rest and during shoulder abduction. Preoperative functional pulmonary tests were performed in 8 patients.

Preoperatively, range of motion of shoulder abduction and flexion were measured. Strength of glenohumeral joint muscles was measured manually during the Horwitz maneuver using the test of motor power on a 0 to 5 scale. The average age at surgery was 27 years (range, 15 to 43 years). Average follow-up was 10 years (range, 3 to 18 years).

\section{Surgical Technique}

All patients underwent surgery under general anesthesia and both shoulders were treated in the same surgical stage. The patient was placed prone and the upper limbs were positioned in $60^{\circ}$ of abduction and $20^{\circ}$ of flexion to lay the scapula flat against the rib cage. Usually, this position was achieved when the medial border of the scapula was at $15^{\circ}$ to $20^{\circ}$ of external rotation relative to the interspinous midline. If a residual deformity was observed, a spacer between the shoulder and the bed was applied to press the scapula more medially.

A linear oblique skin incision was made on the medial border of the scapula. The trapezius muscle was cut. The rhomboid (major and minor) and the elevator scapulae muscles, which usually are atrophic and fibrotic, were detached from the vertebral border of the scapula. The supraspinatus, infraspinatus, subscapularis and serratus anterior muscles were released from the vertebral border of the scapula. Then, $2 \mathrm{~cm}$ of the medial border of the scapula were exposed subperiosteally. The scapula was placed in a more medial and caudal position in order to choose the corresponding ribs to prepare. Four ribs, usually starting from the fourth or fifth, were exposed subperiosteally, taking care to protect the pleura
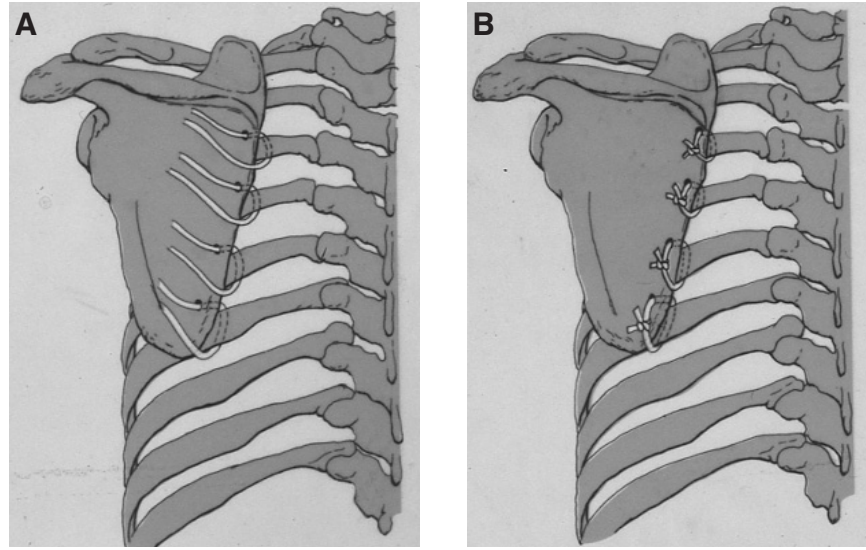

Figure 3. Drawing demonstrating the surgical technique of scapulopexy. (A) A double metal wire is passed under 4 ribs (previously prepared) and through the adjacent hole of the medial border of the scapula. (B) When the medial border of the scapula forms an angle of $15^{\circ}$ to $20^{\circ}$ with the midline, the metal wires are tightened. 


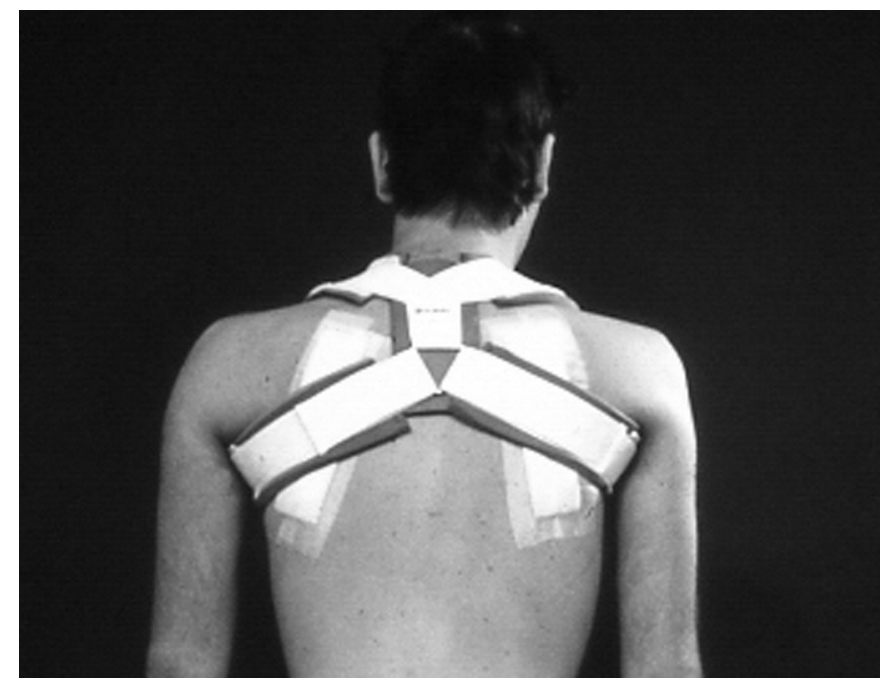

Figure 4. A "figure-eight" dressing is applied postoperatively and it is maintained for 6 weeks.

and the subcostal neurovascular bundles. A double metal wire (1 $\mathrm{mm}$ diameter) was passed under each rib. The scapula was placed over the rib cage to its definitive position and four $2.8 \mathrm{~mm}$ holes were drilled approximately $1.5 \mathrm{~cm}$ from the medial border of the scapula opposite the prepared ribs. One end of each wire was passed through the adjacent hole of the medial border of the scapula. With the scapula held in its final position, the metal wires were twisted and tightened until bone-to-bone contact between the scapula and the ribs was obtained. The wires were cut (figure 3). The muscles were closed over the posterior surface of the scapula and the wound closed routinely. A postoperative radiograph was taken to assess the position of the metal wires and to assess for pneumothorax.

The postoperative management consisted of the application of a "figure eight" dressing immediately after surgery (figure 4). This immobilization was maintained for 6 weeks.
Physiotherapy of the shoulder joint was initiated as soon as tolerated and consisted of isometric deltoid exercises and active exercises in order to strengthen the glenohumeral joint muscles and regain as great a range of motion as possible. Patients were discharged from the hospital 4 to 7 days postoperatively.

All patients were followed monthly for 3 months and then yearly. At the preoperative control, one year after surgery and at last available follow-up, shoulder range of motion in abduction and flexion was evaluated, and a test of motor power was performed. At every follow-up appointment, radiographs of both scapulae were taken to compare the position of the scapula on the rib cage and to check the position and the condition of the metal wires. All patients stated their subjective satisfaction, including functional improvement and cosmesis, according to a visual analogical scale as very satisfied, satisfied, fairly satisfied or unsatisfied.

\section{Results}

All patients experienced improvement in active range of motion of the shoulder. Shoulder abduction improved from an average preoperative value of $70^{\circ}(\mathrm{SD}=20)$ to $98^{\circ}(\mathrm{SD}=18)$ at 1-year follow-up (figure 5A and 5B). Shoulder flexion improved from an average preoperative value of $55^{\circ}(\mathrm{SD}=$ $16)$ to $120^{\circ}(\mathrm{SD}=33)$ at 1 -year follow-up (figure $5 \mathrm{C}$ and $\left.5 \mathrm{D}\right)$. At an average follow-up time of 10 years (range, 3 to 18 years), shoulder abduction decreased to $90^{\circ}(\mathrm{SD}=17)$ and shoulder flexion decreased to $105^{\circ}(\mathrm{SD}=22)($ table 1$)$. The test of motor power showed that at 1-year follow-up muscle strength during shoulder abduction increased from 2.5 preoperatively to 4.5 . Muscle strength during shoulder flexion increased from 2.4 preoperatively to 4.5 . The test of motor power performed at an average follow-up of 10 years (range, 3 to 18 years) showed muscle strength decreased. The mean value of muscle strength was 4 during shoulder abduction and 4.1 during shoulder flexion.

Table 1. Shoulder range of motion.

\begin{tabular}{|c|c|c|c|c|c|c|c|c|}
\hline \multirow{2}{*}{$\begin{array}{l}\text { Patient } \\
\text { Number/ } \\
\text { Gender }\end{array}$} & \multirow{2}{*}{$\begin{array}{c}\text { Age at } \\
\text { Operation } \\
\text { (years) }\end{array}$} & \multicolumn{3}{|c|}{ Flexion (degrees) } & \multicolumn{3}{|c|}{ Abduction (degrees) } & \multirow[b]{2}{*}{$\begin{array}{c}\text { Follow-up } \\
\text { (years) }\end{array}$} \\
\hline & & Preoperative & $\begin{array}{c}\text { 1-year } \\
\text { follow-up }\end{array}$ & $\begin{array}{c}\text { Last } \\
\text { follow-up }\end{array}$ & Preoperative & $\begin{array}{c}\text { 1-year } \\
\text { follow-up }\end{array}$ & $\begin{array}{c}\text { Last } \\
\text { follow-up }\end{array}$ & \\
\hline $1 / F$ & 17 & 70 & 100 & 80 & 70 & 100 & 85 & 15 \\
\hline $2 / F$ & 35 & 45 & 90 & 90 & 60 & 95 & 90 & 15 \\
\hline $3 / \mathrm{M}$ & 26 & 90 & 120 & 105 & 90 & 105 & 100 & 18 \\
\hline $4 / F$ & 15 & 45 & 150 & 100 & 75 & 90 & 80 & 16 \\
\hline $5 / \mathrm{M}$ & 26 & 70 & 120 & 95 & 50 & 90 & 80 & 18 \\
\hline $6 / F$ & 31 & 40 & 80 & 75 & 45 & 60 & 60 & 8 \\
\hline $7 / F$ & 27 & 50 & 100 & 100 & 90 & 110 & 110 & 7 \\
\hline $8 / \mathrm{M}$ & 18 & 45 & 105 & 105 & 45 & 95 & 90 & 6 \\
\hline $9 / F$ & 32 & 60 & 180 & 180 & 90 & 120 & 115 & 5 \\
\hline $10 / F^{*}$ & 30 & 45 & 130 & 120 & 60 & 110 & 100 & 5 \\
\hline $11 / \mathrm{M}^{*}$ & 32 & 70 & 175 & 160 & 70 & 120 & 105 & 4 \\
\hline $12 / M^{*}$ & 43 & 40 & 120 & 90 & 65 & 85 & 70 & 4 \\
\hline $13 / \mathrm{M}^{*}$ & 18 & 60 & 150 & 140 & 75 & 100 & 90 & 3 \\
\hline
\end{tabular}

All data are shown in degrees.

*Indicates patients not included in the previous analysis. 

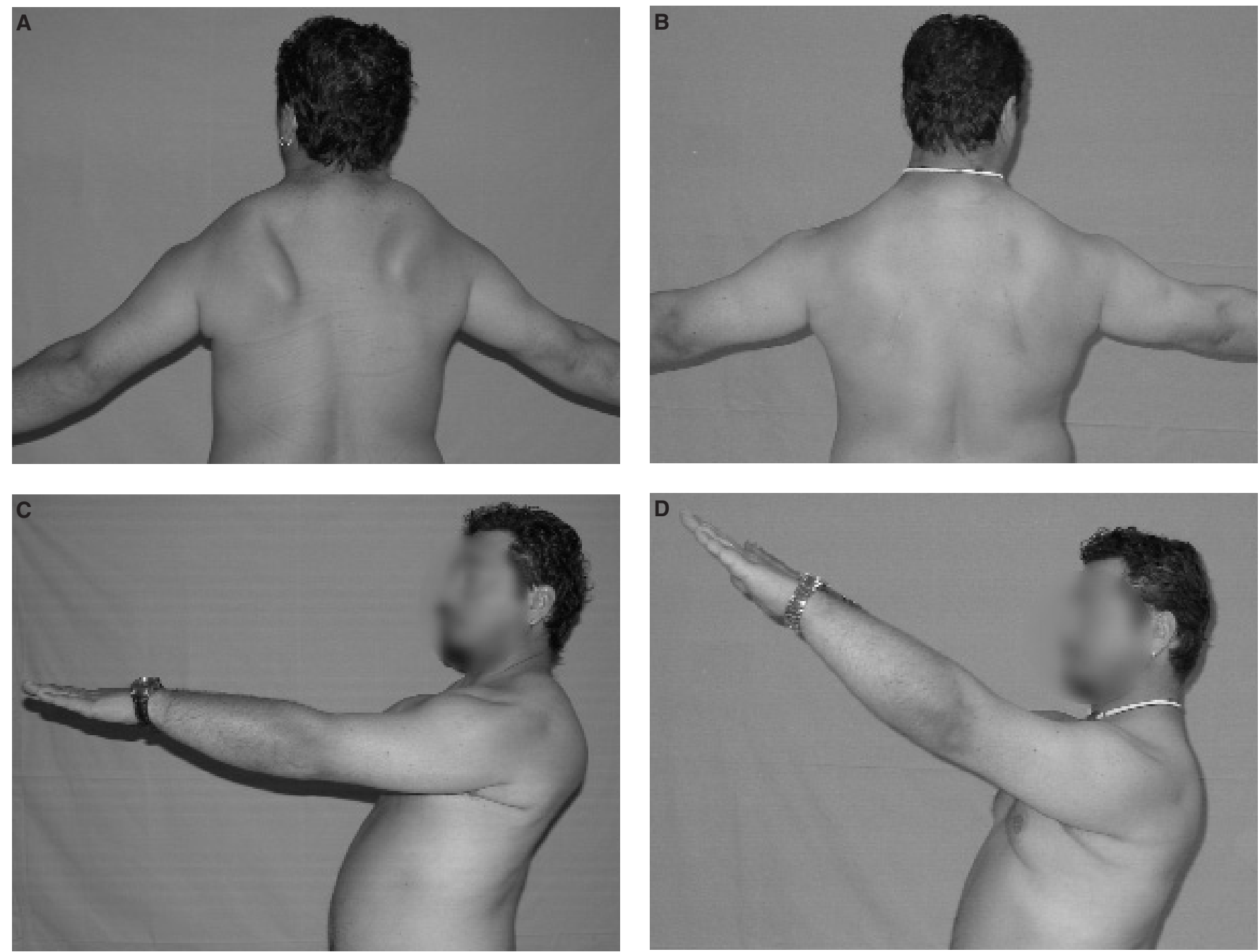

Figure 5. A 30-year-old patient affected by facioscapulomuscular dystrophy. (A) Preoperative active abduction of the shoulders. (B) The patient had good cosmetic and functional results after bilateral scapulopexy. (C) The patient tries to forward flex the arms, but the movement is limited. (D) Improvement of active flexion after bilateral scapulopexy.

All patients were very satisfied with the cosmetic outcome. All patients had clinical improvement with complete resolution of the winged scapula and the shoulders regained a normal shape. Twelve patients stated they were very satisfied with the functional results and one patient was satisfied.

In all 26 cases of scapulopexy, a stable and long-lasting fixation of the scapula to the rib cage was achieved. The position of the scapula was maintained at the last available follow-up, as demonstrated in the radiographs (figure 6). The eight patients who had lung function testing preoperatively, were retested at 1-year follow-up and showed no significant difference of vital capacity.

There were no major surgical complications, except for one patient with unilateral pneumothorax 1-day postoperatively that resolved spontaneously. One patient presented one metal wire breakage at the radiographic routine control seven years after surgery. The scapula remained well fixed to the thorax and the patient did not complain of any symptoms, thus no intervention was performed. One patient fell accidentally three years after surgery because of bilateral drop foot and she had breakage of two metal wires. Functional and clinical improvement were maintained, but pleural pain led to metal wires removal. One patient had a high-impact car accident seven months after surgery with breakage of all wires of the right scapula, representing winged scapula. Revision surgery was performed with the same technique of scapulopexy resulting in very satisfactory clinical and functional improvement at 3-years follow-up.

\section{Discussion}

Winged scapula is the most common clinical presentation of instability of the scapulothoracic joint. Pathological conditions that can lead to winged scapula include FSH muscular dystrophy, ${ }^{1-7}$ congenital elevation of the scapula (Sprengel's disease), traumatic paralysis of the serratus anterior muscle, and polio. ${ }^{26,33}$

Patients affected by FSH muscular dystrophy have a normal life expectancy, so surgical treatment to fix the scapula to the rib cage, improving function, is advisable. $1,2,6,7$ 

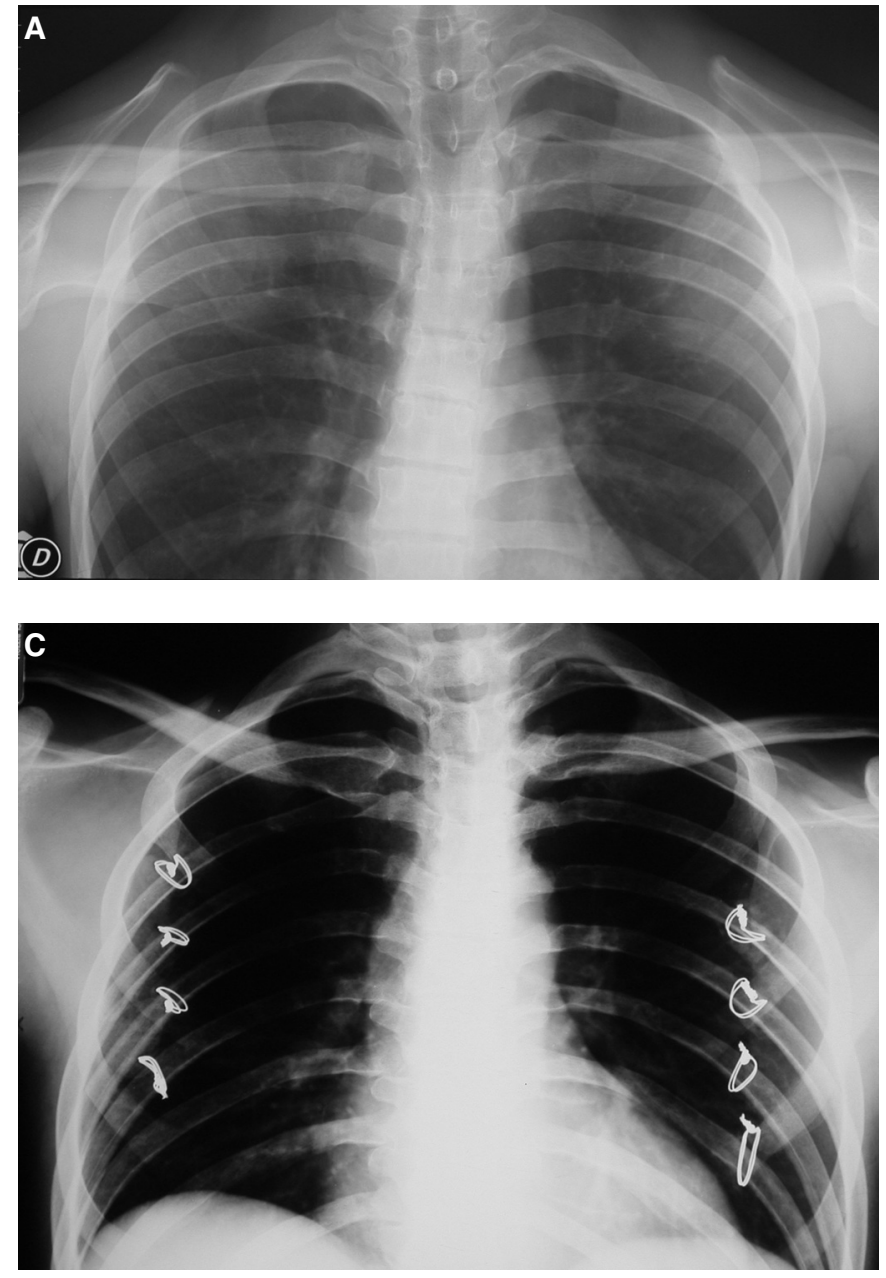

Scapulothoracic fixation can be useful only if the glenohumeral joint muscles are preserved. When the scapula is stabilized to the rib cage, the deltoid contraction is able to abduct and flex the shoulder. However, full shoulder range of motion is not possible because the fixed scapulothoracic joint cannot contribute to the movement.

Several methods of scapulothoracic fixation in FSH muscular dystrophy have been described in the literature. These methods include scapulothoracic fusion or arthrodesis (scapulodesis) ${ }^{12,13,17-27}$ and scapulothoracic fixation without arthrodesis (scapulopexy). ${ }^{14,28-31}$

Different techniques of scapulodesis have been reported using tibial cortical and cancellous bone graft and screws, ${ }^{12}$ metal plates, ${ }^{26,27}$ screws and cancellous bone graft, ${ }^{25}$ and metal wires and bone graft, ${ }^{22}$ with good clinical and functional results which have been maintained over a long period of time. However, being that ribs and scapula are flat bones, they render scapulodesis a demanding technique, causing many complications. In fact, rib fractures, scapula fractures, stress fractures, nonunions, mobilization of the fixation devices, wire breakings and neurologic complications such as brachial plexus palsy, pneumothoraces, hemothoraces, and atelectases have been very often reported.

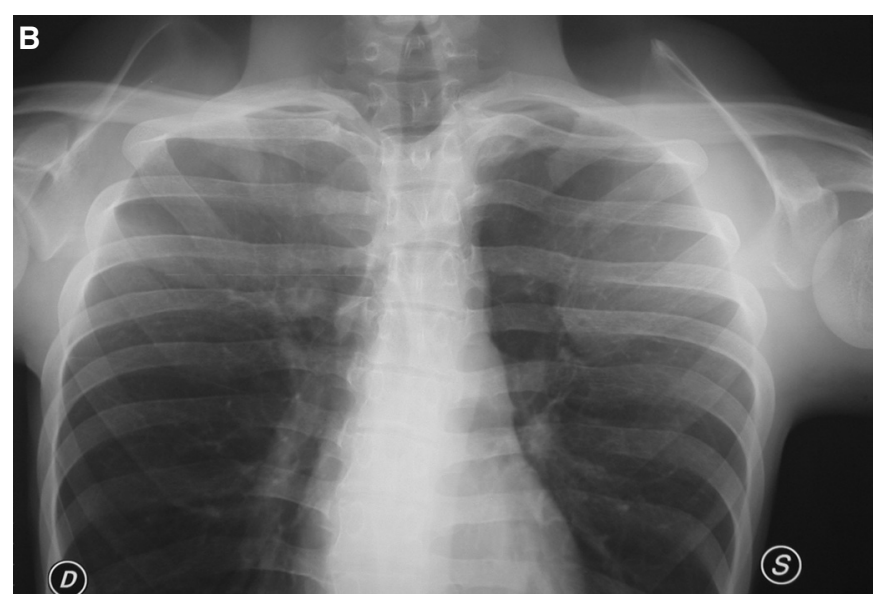

Figure 6. (A) Preoperative radiograph, at rest, of the scapulae of a patient affected by facioscapulohumeral dystrophy. The scapula is internally rotated and its superior border tends to become vertical. (B) Preoperative radiograph of the scapulae during active shoulder abduction. The internal rotation of the scapula and the verticalization of its superior border become more evident. (C) The scapulae, fixed to the ribs by 4 double metal wires, remained in the correct position until last available follow-up.

Scapulopexy is a less rigid fixation than scapulodesis because it leads to scapulothoracic fixation without using bone graft or exposing cancellous bone of the ribs or scapula. There are few reports concerning scapulopexy in FSH muscular dystrophy in the literature. Rinaldi ${ }^{30}$ used strips of fascia lata, Ketenjian ${ }^{31}$ used fascia lata grafts, Mersilene or Dacron strips, and Giannini et al ${ }^{14,29}$ used metal wires tied around the ribs through holes drilled in the medial border of the scapula. Clinical and functional results of these studies were satisfactory. Few complications were reported and included deterioration of fascial slings and wire breakings.

The scapulopexy we used by stabilizing the scapula to the rib cage allowed extensive bone-to-bone contact between the ribs and the scapula that was obtained by firm tightening of four metal wires. Between the scapula and the ribs, a fibrotic scar was formed. This dense fibrotic tissue stabilizes the scapulothoracic joint, but allows micromotion that is responsible for fatigue breakage of the metal wires.

All patients had considerable improvement of shoulder range of motion in abduction and flexion. The improvement in active range of motion depends on the deltoid strength at the time of surgery, which should be at least 4 or 5 . They all had an improvement in doing activities of daily life, did not complain of easy fatigue and were very satisfied with the cosmetic result. The scapulothoracic fixation persisted with time, so the cosmetic results, and the minimized fatigue and discomfort were long-lasting. However, being that FSH muscular dystrophy is a progressive myopathy, it can cause very slow deltoid weakening that may lead to a diminishing shoulder range of motion. 
The complications strictly associated to the surgical technique used in this series were one pneumothorax, which resolved spontaneously, and one wire breakage without trauma. Unfortunately, two patients experienced a trauma that, in one case, was of low entity and led to wire breakage without loss of the scapulothoracic fixation. In the second case, a high impact car accident caused monolateral breakage of all wires and winged scapula, and therefore needed revision.

In order to obtain good functional results by scapulothoracic fixation, the position of the scapula to the rib cage is very important. If the scapula is fixed too caudally, neurological complications such as stretching of the brachial plexus can occur. ${ }^{34}$ A scapula fixed in an adducted position limits the function of the glenohumeral joint, while if it is fixed in an abducted position, the patient is able to move the glenohumeral joint through more functional range of motion. An excessively abducted or rotated scapula causes an abnormally high shoulder. Diab et al ${ }^{27}$ fixed the scapula with its vertebral border externally rotated at an angle of $25^{\circ}$ to the midline. Krishnan et $\mathrm{al}^{26}$ reported that ideal positioning of the scapula is in the $20^{\circ}$ to $25^{\circ}$ external rotation relative to the midline. We obtained good functional results without neurological complications by fixing the scapula $15^{\circ}$ to $20^{\circ}$ between its medial border and the interspinous line.

\section{Conclusion}

Winging of the scapula in FSH muscular dystrophy is caused by weakness of the muscles that stabilize the scapula to the rib cage. Surgical operations aim to fix permanently the scapula to the ribs using different techniques and devices. The benefits from surgery have to be balanced against the potential postoperative complications. The scapulopexy used in this extended series of patients consisted of repositioning the scapula and fixing it to four ribs by using metal wires without performing arthrodesis. All patients obtained a very satisfactory cosmetic result, functional improvement in shoulder abduction and flexion, and stabilization of the scapulothoracic fixation over time. This technique has a small rate of complications. It is reproducible, safe and effective, resulting in clinical and functional improvement.

\section{Acknowledgments}

We would like to thank the physiotherapist, Olivia Faldini, for her invaluable work in evaluating the patients at follow-up and assistance in writing the manuscript.

\section{References}

1. Dubowitz V. The muscular dystrophies In: Muscle disorders in childhood, 2nd ed. London: WB Saunders Company LTD; 1995. 111-119.

2. Fitzsimons RB. Facioscapulohumeral muscular dystrophy. Curr Opin Neurol 1999;12:501-511.

3. Hughes MI, Hicks EM, Nevin NC, Patterson VH. The prevalence of inherited neuromuscular disease in Northern Ireland. Neuromuscul Disord 1996;6:69-73.

4. Merlini L, Forst J. Surgical management of muscular dystrophy. In: Emery AE, ed. The muscular dystrophies. New York; Oxford University: 2001. 284-296.
5. Tawil R, Figlewicz DA, Griggs RC, Weiffenbach B. Facioscapulohumeral dystrophy: a distinct regional myopathy with a novel molecular pathogenesis. FSH Consortium. Ann Neurol 1998;43:279-282.

6. Kissel JT. Facioscapulohumeral dystrophy. Semin Neurol 1999; 19:35-43.

7. Tonini MM, Passos-Bueno MR, Cerqueira A, Pavanello R, Vainzof M, Dubowitz V, Zatz M.. Facioscapulohumeral (FSHD1) and other forms of muscular dystrophy in the same family: is there more in muscular dystrophy than meets the eye? Neuromuscul Disord 2002;12:554-557.

8. Nelson MR. Rehabilitation concerns in myopathies. In: Braddom RL, ed. Physical medicine and rehabilitation. Philadelphia, PA: W B Saunders Co; 1996. 1012-1013.

9. Bagg SD, Forrest WJ. A biomechanical analysis of scapular rotation during arm abduction in the scapular plane. Am $\mathrm{J}$ Phys Med Rehabil 1988;67:238-245.

10. Inman VT, Ralston HJ, Todd F. Human walking. Baltimore, MD: Williams \& Wilkins; 1981. 96-97.

11. Siegel IM. Muscle and its desease: an outline primer of basic science and clinical method. Chicago, IL: Year Book Medical; 1986. 252-254.

12. Copeland SA, Howard RC. Thoracoscapular fusion for facioscapulohumeral dystrophy. J Bone Joint Surg Br 1978;60-B:547-551.

13. Copeland SA, Levy O, Warner GC, Dodenhoff RM. The shoulder in patients with muscular dystrophy. Clin Orthop Relat Res 1999;(368):80-91.

14. Giannini S, Ceccarelli F, Faldini C, Pagkrati S, Merlini L. Scapulopexy of winged scapula secondary to facioscapulohumeral muscular dystrophy. Clin Orthop Relat Res 2006;449:288-294.

15. Barnett ND, Mander M, Peacock JC, Bushby K, GardnerMedwin D, Johnson GR. Winging of the scapula: the underlying biomechanics and an orthotic solution. Proc Inst Mech Eng [H] 1995;209:215-223.

16. Mummery CJ, Copeland SA, Rose MR. Scapular fixation in muscular dystrophy. Cochrane Database Syst Rev 2003;(3):CD003278.

17. Toni A, Merlini L, Sudanese A, Baldini N, Granata C. Thoraco-scapular arthrodesis in facioscapulohumeral dystrophy. Chir Organi Mov 1986;71:127-131.

18. Twyman RS, Harper GD, Edgar MA. Thoracoscapular fusion in facioscapulohumeral dystrophy: clinical review of a new surgical method. J Shoulder Elbow Surg 1996;5:201-205.

19. Andrews CT, Taylor TC, Patterson VH. Scapulothoracic arthrodesis for patients with facioscapulohumeral muscular dystrophy. Neuromuscul Disord 1998;8:580-584.

20. Berne D, Laude F, Laporte C, Fardeau M, Saillant G. Scapulothoracic arthrodesis in facioscapulohumeral muscular dystrophy. Clin Orthop Relat Res 2003;(409):106-113.

21. Bunch WH. Scapulo-thoracic fusion. Minn Med 1973;56: 391-394.

22. Bunch WH, Siegel IM. Scapulothoracic arthrodesis in facioscapulohumeral muscular dystrophy. Review of seventeen procedures with three to twenty-one-year follow-up. J Bone Joint Surg Am 1993;75:372-376.

23. Howard RC. Thoraco-scapular arthrodesis. J Bone Joint Surg 1961;43-B:175.

24. Jakab E, Gledhill RB. Simplified technique for scapulocostal fusion in facioscapulohumeral dystrophy. J Pediatr Orthop 1993;13:749-751.

25. Letournel E, Fardeau M, Lytle JO, Serrault M, Gosselin RA. Scapulothoracic arthrodesis for patients who have fascioscapulohumeral muscular dystrophy. J Bone Joint Surg Am 1990;72:78-84. 
26. Krishnan SG, Hawkins RJ, Michelotti JD, Litchfield R, Willis RB, Kim YK. Scapulothoracic arthrodesis: indications, technique, and results. Clin Orthop Relat Res 2005;(435):126-133.

27. Diab M, Darras BT, Shapiro F. Scapulothoracic fusion for facioscapulohumeral muscular dystrophy. J Bone Joint Surg Am 2005;87:2267-2275.

28. Putti V. L'osteodesi interscapolare in un caso di miopatia atrofica progressiva. Arch Ortop 1906;23:319-331.

29. Giannini S, Ceccarelli F, Coppola G. Fissazione chirurgica della scapola nella distrofia facio-scapolo-omerale. Progressi in patologia vertebrale 1992;XIII:283-288.

30. Rinaldi F: Terapia chirurgica nella forma "facio-scapoloomerale" della distrofia muscolare primitiva. Clinica Ortopedica 1964;16:233-243.

31. Ketenjian AY. Scapulocostal stabilization for scapular winging in facioscapulohumeral muscular dystrophy. J Bone Joint Surg Am 1978;60:476-480.

32. Horwitz MT, Tocantins LM. Isolated paralysis of the serratus anterior (magnus) muscle. J Bone Joint Surg Am 1938;20:720-725.

33. Whitman A. Congenital elevation of the scapula and paralysis of serratus magnus muscle. JAMA 1932;99:1332-1334.

34. Mackenzie WG, Riddle EC, Earley JL, Sawatzky BJ. A neurovascular complication after scapulothoracic arthrodesis. Clin Orthop Relat Res 2003;(408):157-161.

\section{Author Affiliations}

Sandro Giannini, MD

Department of Orthopaedic Surgery

University of Bologna, Istituto Ortopedico Rizzoli, Italy

Via G. Pupilli 1, 40136 Bologna, Italy

Cesare Faldini, MD

Department of Orthopaedic Surgery

University of Bologna, Istituto Ortopedico Rizzoli, Italy

Via G. Pupilli 1, 40136 Bologna, Italy

Stavroula Pagkrati, $M D$

Department of Orthopaedic Surgery

University of Bologna, Istituto Ortopedico Rizzoli, Italy

Via G. Pupilli 1, 40136 Bologna, Italy

Gianluca Grandi, MD

Department of Orthopaedic Surgery

University of Bologna, Istituto Ortopedico Rizzoli, Italy

Via G. Pupilli 1, 40136 Bologna, Italy

Vitantonio Digennaro, $M D$

Department of Orthopaedic Surgery

University of Bologna, Istituto Ortopedico Rizzoli, Italy

Via G. Pupilli 1, 40136 Bologna, Italy
Deianira Luciani, $M D$

Department of Orthopaedic Surgery

University of Bologna, Istituto Ortopedico Rizzoli, Italy

Via G. Pupilli 1, 40136 Bologna, Italy

Luciano Merlini, $M D$

Muscle Unit, Division of Medical Genetics

Department of Experimental and Diagnostic Medicine

University of Ferrara, Italy 